\title{
U.S. EDUCATIONAL SERVICES INCORPORATED
}

$\mathrm{E}^{\mathrm{B}}$ DUCATIONAL Services Incorporated of Watertown, Mass., a non-profit educational research organization which originated as the Physical Science Study Committee under the auspices of the Massachusetts Institute of Technology in 1956, has been awarded a grant of $1,000,000$ dollars by the Ford Foundation.

Responding to the need for improving curricula in American schools, Educational Services Incorporated has initiated the improvement of projects in many disciplines; it also participates in various educational programmes overseas, including the new Indian Institute of Tech. nology, at Kanpur, and in emergent countries in tropical Africa.

Curriculum reform programmes are now being conducted in the teaching of science in the elementary grades and in developing a social studies and humanities curriculum applicable at all grade levels. In addition to these and other programmes in the primary and secondary schools, Educational Services Incorporated is assisting in the development of new techniques and methods of teaching science and engineering in the universities. The organization also offers administrative support to the National Commission on Engineering Education.

Educational Services Incorporated was founded in 1958 to handle the expanding Physical Science. Study Committee programme and to provide administrative guidance and support for other course content improvement projects. The Committee course, formed in 1956 by Prof. Jerrold R. Zacharias, professor of physics in the Massachusetts Institute of Technology, and the late Prof. Francis L. Friedman, also a professor of physics in the Institute, has revolutionized the teaching of high-school physics. The course is now being taught to about 135,000 students in the United States, or approximately 30 per cent of those taking high-school physics.

Physicists and educators at many universities contributed to this course, including groups from the University of Illinois, Cornell University, Bryn Mawr College, Educational Testing Service of Princeton, Now Jersey, Harvard University, the Massachusetts Institute of Technology, and other schools. Material supplied by the course has been translated into Swedish, Norwegian, Italian, Japanese, Hebrew, Spanish and Portuguese. It has also been translated into French for use in Canada. Further translations are being prepared in Danish and Turkish.

The Physical Science Study Committee course is notable not just for the text-book which stresses basic concepts of physics and carries high-school students into modern physics, but also because of the coherence and variety of the accompanying teaching aids, including films, examinations, laboratory apparatus and laboratory experiments. So far, fifty-three films made by the course have been produced by Educational Services Incorporated with many of the nation's leading physicists serving in principal roles in demonstrating some of the basic concepts of physics. Some of the films are now being adapted for college use.

The Science Study Series, published by Doubleday Anchor Books with the editorial counsel of Educational Services Incorporated, provides collateral reading for science students. This series of paporbacks includes biographies of famous scientists and their roles in the development of fundamental physical concepts. Teachertraining institutes for high-school physics teachers in the United States and in many nations overseas have also boon. organized.
In addition to the Physical Science Study Committee, Educational Services Incorporated is now developing programmes in the following areas.

Elementary Science Study. Physicists, chemists, biologists, mathematicians and scientists from other disciplines are participating in the preparation of material for the elementary grades. This material includes text, films, the development of experiments for classroom use, and the inauguration of teacher-training programmes to introduce a study of science in the elementary school curriculum. Some of the topies being studied this year in experimental classes at selected schools in New Jersey, Pennsylvania, Delaware, Oregon, New York and the District of Columbia, include micro-ecology, plant growth, elementary physics, and laboratory science. More than one hundred scientists and educators in the United States and overseas are associated in the preparation of pre. liminary material.

Kanpur Indo-American Programme. The Indian In. stitute of Technology at Kanpur, about two hundred miles south-east of New Delhi, is being developed by the Government of India into a major centre for education and research in engineering and science. Now in its second year of operation, the Institute offers undergraduate programmes in physies, chemistry, mathematies, and civil, electrical, chemical, mechanical and metallurgical engineering. It is expected that graduate courses will be given in the next few years.

At the request of the Government of India, nine leading American universities are assisting in the development of the Indian Institute. Because the resources of a single American university would be severely overtaxed if it were to furnish the sustained effort required to carry out the United States commitment at the Institute, a consortium of universities was formed in April 1962. Educational Services Incorporated administers the project contract which is financed by the United States Agency for International Development. The participating universities are California Institute of Technology, Carnegie Institute of Technology, Princeton University, the University of Michigan, the University of California, Purdue University, Ohio State University, Case Institute of Technology, and the Massachusetts Institute of Technology. Twelve American staff members are now toaching at the Institute. It is expected that this number will be doubled towards the end of 1963.

Indian plans for the Institute, which now has a staff of 40 and approximately 200 undergxaduates, provide for 1,600 undergraduates, 400 graduate students, and a staff of about 250 .

African Education Study. Educational Services Incorporated, following two major conferences in Africa at Accra, Ghana, in 1961, and at Entebbe, Uganda, in 1962, is engaged in a broad programme designed to help emergent countries in tropical Africa to assess their educational needs in the future in mathomaties, in the sciences, in languages, and in the social studies and humanities.

Text material in mathomatics, prepared by Educational Services Incorporated, including representatives from tho Stanford University Arithmotic Programme, is being used in preliminary trials in many African schools now beginning.

The African Education Programmo is developing as a partnership between the African educationists and those from the United States and Great Britain. In this ondeavour Educational Services offers especially the organ- 
ization's experience with course content improvement programmes.

Commission on Engineering Education. Members of this Commission include many leading representatives from industry, Government, and education. The Commission was formed at a meeting at Boulder, Colorado, in 1961 .

The headquarters of the Commission in Washington function as a point of co-ordination for the members. The Commission is developing educational resources of particular relevance to fundamental fields of engineering, including all types of educational resources and procedures which involve both students and faculty in the areas of design, data processing and decision making.

Semiconductor Electronics Education Committee. The teaching programme of this Committeo-now being used for the first time, in its preliminary form, at eleven universities in the United States and Great Britaindemonstrates introductory semiconductor physics, the principles of semiconductor devices, and the most important features of electronic circuit design and construction which use semiconductor devices. It is intended that the final material produced by the Committee will be used in either the junior or senior year of college.

The Committee's presentation includes text material in the form of a series of six paperback books on the principles and applications of semiconductors; the development of home laboratory experiments; take-home laboratory kits; a series of formal laboratory experiments; and a set of films both complementary and supplementary to the texts.

National Committee for Fluid Mechanics Films. The films in fluid mechanies produced by this Committee are being used at more than sixty universities and Government institutions in improved teaching of aeronautical and astronautical engineering, and in chemical, civil, mechanical and marine engineering. The films are also being used in the instruction of meteorology, applied mathematics, and in medicine. The first two major films produced, The Fluid Mechanics of Drag and Vorticity, are being used at univorsities in the United States, Ghana, Great Britain, Australia, Canada, Israel and Holland.

Social Studies and Humanities. This programme exolved from a conference sponsored by Educational Services Incorporated at Dedham, Massachusetts, in the summer of 1962. Participants at the conference represented the humanities and the social sciences, including literature, history, art, music, Latin and Groek, as well as sociology and psychology. The consideration of the possible revision of the present social studies and humanities curricula is the aim of this programme, which is not yet fully implemented. Investigations are being made of the individual humanistic disciplines with the view of focusing the major ideas of the past and present into a presentable, coherent framework which may then, using some of the techniques developed by the behavioural scientists, be taught most effectively.

\section{SOLVENT EXTRACTION CHEMISTRY}

A SYMPOSIUM on "Solvent Extraction Chemistry" was held at Gatlinburg, Tennessee, during October 23-26, by invitation of the Oak Ridge National Laboratory. The purpose of the symposium was to bring together persons engaged in investigating solvent extraction and to provide for the interchange of information, not merely through the papers presented, but also in an open session and by informal discussions.

The presentation of thirty-two papers submitted from laboratories in the United States, Great Britain, France, Sweden and Italy in a programme which filled four days is a measure of the expansion of work in this field since the one-day symposium (Nature, 172,$149 ; 1953$ ), arranged by Atomic Energy Research Establishment, Harwell, in 1953. In the intervening period, the chemistry of solvent extraction has been included in conferences of wide scope, such as the International Conferences on the Peaceful Uses of Atomic Energy at Geneva in 1955 and 1958; in these, the chemical aspects have generally taken second place to flowsheets and processing problems.

Dr. F. L. Culler, head of the Chemical Technology Division, Oak Ridge National Laboratory, in his opening remarks pointed out that the progress achieved by research in the past decade had made solvent extraction an important and powerful technique for solving the separation, purification and recovery probloms that occurred in the field of atomic energy. Solvent extraction had moved forward from the uso of diethyl ether to separate uranium from contaminating metals to being a versatile techniquo applied to the soparation of closely related inorganic compounds in a variety of acid media: separations could if necessary now be achieved in a matter of seconds rather than minutes. Dr. Culler foresaw the time when its use for separations of biological substances would be greatly oxtended.

Organo-phosphorus compounds, which were grouped as 'neutral' or 'acidic', formed the subject of several papers presented by the members of the Argonne National Laboratory, Atomic Energy Research Establishment, Harwell, Oak Ridgo National Laboratory and the General
Electric Co. Laboratories at Hanford. The neutral class extract metals and acids: the former mainly by solvation $\equiv \mathrm{P}=\mathrm{O} \rightarrow M$, there being replacement of aquo groups from the co-ordination sphere; the latter by hydrogen bonding. The extractive power of these compounds has been correlated with their basicity, which is reflected in a number of properties such as the frequency of the infrared stretching vibration of the PO group: the extraction order is phosphine oxides > phosphinates > phosphonates > phosphates.

The phosphates, though relatively weak as extractants, are ideal for many separation processes as recovery from the organic phase is usually easy: tributyl phosphate (TBP) has been extensively studied on account of its versatility, and the part played by ions and ion-pairs in TBP systems has been recognized. Increased attention has been paid to the influence of the polarity of the diluent, often a hydrocarbon, on the distribution coefficionts. Among these neutral compounds, phenyl phosphonates have been found to have enhanced selectivity for the separation of certain metals, while phosphine oxides are suitable for small-scale laboratory separations and for analytical purposes. Other compounds included in the reviews wore certain diphosphonates found to be very powerful extractants, and thiophosphates.

The main impression given by the papers dealing with the acidic organo-phosphorus compounds as extractants was the variety of mechanisms that have been found to occur. Thus the metal complexes obtainod with the monoacidic phosphates, $H X$, may contain: (1) the unit $X$ as a monodentate or as a bidentate group; (2) the group $\mathrm{HX}_{2}{ }^{-}$derived from the dimer of $\mathrm{HX}$; (3) the neutral group, $H X$, co-ordinated through its phosphoryl oxygen; (4) the anion, for example, $\mathrm{NO}_{3}^{-}$, present in the aquoous phase. In viow of the interaction of the noutral compounds (for example, TBP) with HX and of their ability to form solvates, it is not surprising that the extracting power of a mixture of a neutral compound and $\mathrm{HX}$ is often considerably different from that of $H X$ alono. 